\title{
KONTROL SUHU MESIN VACUUM FORMING OTOMATIS ANEKA BENTUK KEMASAN DENGAN HMI
}

\author{
Sonki Prasetya ${ }^{1}$, Hasvienda M. Ridlwan, Muslimin, Sugeng Mulyono, Idrus \\ Assagaf \\ Jurusan Teknik Mesin, Politeknik Negeri Jakarta, Kampus Baru UI Depok, 16425 \\ e-mail : ${ }^{1}$ sonki.prasetya@mesin.pnj.ac.id
}

\begin{abstract}
Food industries in a country depend on the packaging system to preserve the product commonly use the plastic based material. Generally, commercial plastic type for packaging in Indonesia are Polystirine (PS) and Polyvinyl Chlorida (PVC). One of problem in home industries (UKM) especially in food sectoris to find the appropriateand particular packaging for their food products. Vacuum Thermoforming machines commonly used by industries to provide the packaging product. However, the forms and materials for the product are too general. In order to provide specific forms for definite products, small-scale vacuum forming machines produced by other countries can be found in the market. Nevertheless, the price still considered high for a home industrial entrepreneur. This study investigates the appropriate automatic control system for the designed small-scale industrial vacuum forming. The control decision achieved via a software based on LabView through a laptop. Thus, it can be displayed, monitored and also being recorded continuously. The test shows that the heater stable at 20 minutes meanwhile the plastic sheet can be shapedafter 15 minutes heating process.
\end{abstract}

Keywords: Plastic, vacuum forming, home industry, automatic.

\begin{abstract}
ABSTRAK
Industri makanan yang jumlahnya cukup besar di Indonesia tidak dapat lepas dari proses pengemasan terutama penggunaan kemasan plastik. Jenis plastik yang banyak digunakan untuk kemasan makanan adalah Polystirine (PS)dan Polyvinyl Chlorida (PVC) yang umumnya dijual bebas di pasar/ toko dengan ukuran yang sudah spesifik. Masalah yang banyak dihadapi oleh industrik kecil menengah (UKM) umumnya adalah kesulitan dalam penggunaan kemasan yang sesuai baik ukuran maupun bentuk dari produknya. Mesin Vacuum Thermoforming seperti yang dimiliki oleh industri untuk produk kemasan umumnya memiliki skala yang besar dan memiliki jenis serta bentuk standar. Sementara mesin dalam skala kecil masih dirasa cukup mahal dari segi biaya karena produk dari negara luar. Karenanya mesin Vacuum Forming otomatis skala UKM dengan biaya yang ekonomis ini sangat penting. Penelitian ini ditujukan untuk melakukan otomatisasi dari karakter pemanas yang digunakan dengan mempertimbangkan posisi optimal agar dicapai unjuk kerja yang optimal dari system yang sudah dibuat. Keputusan dari pengendalian alat dilakukan menggunakan software LabView melalui laptop. Oleh sebab it, data dapat ditampilkan, dimonitor serta disimpan secara langsung dan terus-menerus. Hasil uji fungsi menunjukkan bahwa pemanas bekerja dengan stabil setelah 20 menit sedangkan obyek plastik dapat dibentuk setelah dipanaskan selama 15 menit.
\end{abstract}

Kata kunci: Plastik,,Vacuum Forming, UKM, otomatis.

\section{PENDAHULUAN}

Penggunaan plastik sebagai kemasan ini semakin meningkat setiap tahunnya dan beresiko terhadap pencemaran lingkungan dikarenakan sifat plastik yang tidak mudah terurai [1-3]. Di Negara berkembang seperti Indonesia dimana jumlah peningkatan penduduk sangat tinggi, peningkatan industri makanan dan minuman secara tidak langsung berpengaruh pada penggunaan plastik yang semakin banyak. Data yang diperoleh dari Kementrian Perindustrian menunjukkan bahwa pertumbuhan industri plastik terutama dari sector kemasan makanan dan minuman 
menyumbangkan porsi $68 \%$ dari total industri kemasan pada 2015 [4].

Industri makanan tidak lepas dari kemasan untuk digunakan sebagai wadah menyimpan makanan disamping dari sisi menjaga kebersihan makanan. Kemasan yang ada dipasaran memiliki bentuk dan material yang sudah tertentu. Hal ini akan membuat bentuk dan jenis makanan menjadi terbatas jika ingin mengikuti kemasan yang sudah umum tersedia. Karenanya industri ini memerlukan solusi untuk dapat membuat kemasan sesuai dengan produk makanan yang spesifik baik bentuk maupun penanganannya.

Alat pembuat kemasan umumnya berukuran besar dan digunakan industri pembuat kemasan. Adapun kemasan khusus jika diinginkan memerlukan pemesanan dalam jumlah besar karena biaya yang mahal. Jika produk makanan masih sedikit jumlahnya, maka kemasan khusus akan menjadi masalah bagi industri kecil. Saat ini mesin kemasan skala kecil sudah dapat dibeli pada toko mesin industri, hanya saja biaya masih dirasa tergolong mahal salah satu alasannya adalahdikarenakanmerupakan produkdari luar Indonesia.

Atas dasar hal tersebut maka dibuat mesin pembuat kemasan dengan metode Vacuum Thermoforming atau dapat disebut juga Vacuum Forming dengan komponendari dalam negeri. Untuk membantu sekaligus efisiensi aktifitas bagi pengguna, maka otomatisasi diterapkan pada mesin ini. Oleh sebab itu, dengan fasilitas Human Machine Interface (HMI) melalui media computer/ laptop yang terhubung dengan mesin akan membuat pengguna tidak kesulitan dalam mengendalikan dan mengoperasikannya.

Tujuan dari penelitian ini adalah untuk mendapatkan karakterisasi sistem kendali pada mesin vacuum thermoforming dengan tepat untuk dilakukan proses pengendalian (control) menggunakan sistem otomatis, agar mempermudah pengoperasian oleh pengguna, parameter-parameter penting yang didapat disajikan dalam sistem Human Machine Interface (HMI) dan terdokumentasi dan sebagai tambahan, biaya operasional dari alat tidak mahal.

Adapun focus control yang akan dibahas pada penelitian ini adalah pada pembuatan bagian kendali temperatur dengan menggunakan HMI. Pengendalian aktuator dan penetapan desain mekanik tidak akan detail dipaparkan pada kesempatan ini.

\section{METODE PENELITIAN}

Studi ini memerlukan capaian kegiatan dalam rangka mendapatkan tujuan. Pada Gambar 1 adalah langkah-langkah yang dilakukan pada penelitian ini.

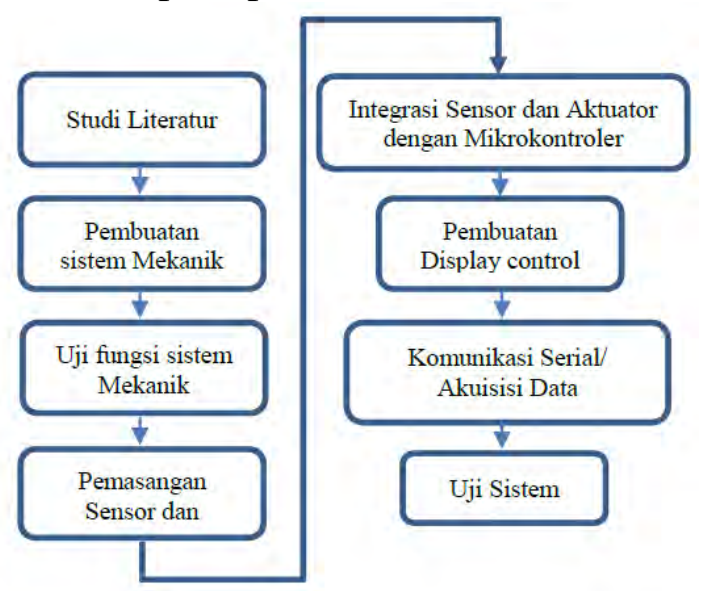

Gambar 1. Kegiatan studi Vacuum Forming.

Sebagai langkah awal dalam pembuatan alat ini maka dilakukan survey terhadap beberapa mesin Vacuum thermoforming yang sudah ada di pasaran.alat sejenis yang dijadikan sebagai pembanding seperti: Formech 2240[5], Starview's SAT Series[6], Vacuum Former 725 FLB[7]. Dari survei tersebut selanjutnya dibuat desain mekanik dari system seperti pada Gambar 2. Adapun keterangan pada gambar terrsebut adalah: 1. Rangka Mesin, 2. Heater, 3. Clamp, 4. Wire Bracket, 5. Rope, 6. Vacuum Plate, 7. Dudukan Vacuum Plate, 8. Panel Box9. Papan Kontrol, 10.LCD Display, 11. Clamp Control, 12. 
Saklar Heater, 13. Saklar Vacuum, 14. Pengunci Clamp, 15. Bracket Motor Stepper, 16. Motor Stepper, 17. Tutup Atas, 18. Bracket Motor Vacuum, 19. Motor Vacuum, 20. Bearing.
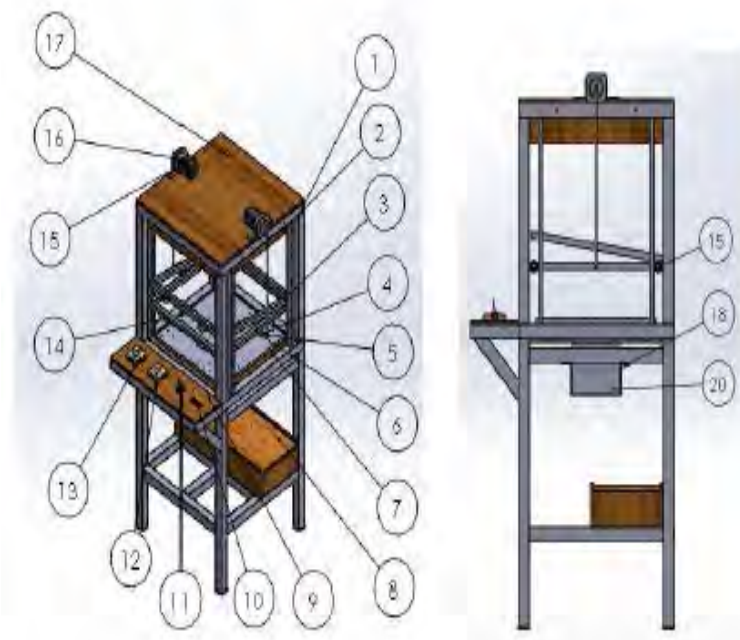

Gambar 2.Rancangan mekanik sistem mesin Vacuum Forming

Pengoperasian alat adalah sebagai berikut. Saat pertama kali mesin diaktifkan, maka kondisi clamp (3) yang diberikan lembar plastik berada di bawah dan proses pemanasan dimulai. Dimana sesuai dengan kriteria plastik, maka heater akan menjaga temperature sesuai dengan temperature pembentukan plastik. Jika temperature yang sesuai sudah dicapai, maka lembar plastik yang diletakkan pada clamp akan bergerak menuju heater lalu jika lembar plastik sudah dapat dibentuk (panasnya sesuai kriteria) maka clamp diturunkan menuju vacuum plate yang sudah diberi cetakan. Selanjutnya plastik yang akan dibentuk akan melingkupi cetakan sementara bagian bawah dari vacuum plate (7) terdapat motor vacuum yang berfungsi untukmenyerap udara disekeliling cetakan agar dapat mengikuti kontur cetakan dengan rapat.

Metode penelitian dilakukan dengan pendekatan eksperimental, data diperoleh dengan cara pengujian yang bertujuan untuk mendapatkan parameter-parameter proses yang tepat untuk mendapatkan jumlah komponen dan bahan yang optimal agar biaya produksi dan operasional penggunaan alat menjadi ekonomis tercapai.

Dari desain mekanik yang direalisasikan seperti Gambar 3 tersebut, maka kendali sistem otomatis untuk mempermudah operator dapat mulai dirancang.

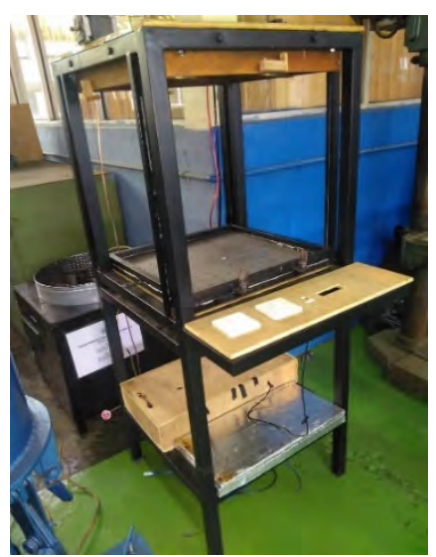

Gambar 3. Rancangan mekanik sistem mesin Vacuum Forming

Komponen utama dapat dibagi menjadi dua pokok bagian:

1. Input adalah sarana yang diperlukan untuk indicator dari prosesor atau pemberi keputusan.

2. Output adalah sarana yang diperlukan untuk melakukan tindakan dari hasil keputusan

\section{Pemilihan Komponen}

Untuk merealisasi kendali alat ini, maka dilakukan pemilihan/penetapan komponen dan sistem kendali dari mesin. Berikut adalah beberapa komponen yang digunakan dalam system.

\section{Sensor suhu Thermocouple}

Sensor suhu berfungsi untuk mengubah perubahan temperatur menjadi perubahan tegangan pada bagian outputnya. Sensor suhu Thermocouple tipe $\mathrm{K}$ dengan pengkondisi sinyal MAX 6675 seperti Gambar 4 memiliki spesifikasi menggunakan tegangan maksimal 5 
volt, dan temperatur operasinya 0$600^{\circ} \mathrm{C}[8]$.

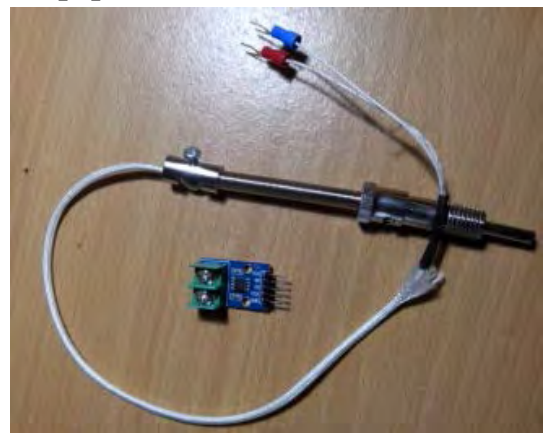

Gambar 4. Thermocouple Type-K

Sensor posisi/ Limit Switch

LimitSwitch merupakan saklar yang dilengkapi lever yang berfungsi untuk menggantikan saklar seperti Gambar 5. Prinsip kerja dari limitswitch seperti saklar pada saat lever ditekan maka secara otomatis arus listrik ke motor

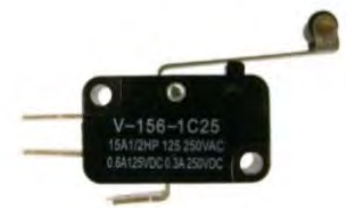

stepper berhenti. Limitswitch ini difungsikan sebagai sensor posisi untuk obyek bergerak[9].

Gambar 5. Sensor Limit Switch Motor Stepper

Motor Stepper adalah salah satu tipe motor listrik yang digunakan untuk penggerak atau aktuator. Motor stepper adalah motor DC yang tidak mempunyai komutator.

Motor stepper digerakkan dengan dengan bantuan driver TB6560 sebagai sistem pengatur kontrol torsi, kecepatan, dan langkah yang dilakukan oleh motor stepper. Dengan pulsa yang diberikan oleh pengguna,dibutuhkan 200 pulsa tiap putaran yang akan digunakan untuk mengangangkat clamp.

Berdasarkan hasil rancangan clamp didapatkan bahwa berat clamp sebesar $3.5 \mathrm{~kg}$, maka didapatkan spesifikasi penggerak yang paling sesuai dengan beban clamp yaitu menggunakan motor stepper dengan pemilihan motor sesuai perhitungan di bawah ini. Torsi (T) merupakan perpaduan gaya (F) pada jarak lengan tertentu (L).

$$
\begin{aligned}
& T=F \times L \\
& T=m . g \times L \\
& T=3,5[k] \times 9,81\left[\frac{m}{s^{2}}\right] \times \frac{5,8}{2 \times 1000} \\
& 0,9957[N]
\end{aligned}
$$

Motor yang dipilih adalah Nema tipe SY57STH56-1006A seperti Gambar 6[10]memiliki kekuatan maksimal dari motor stepper tersebut dengan tegangan listrik 7.4 (V) dan dengan arus listrik 1 (A).

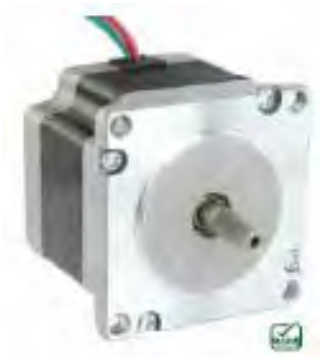

Gambar 6. Motor Nema 23[10].

\section{Pemanas}

Pemanas / heater merupakan sarana output yang dipakai untuk memberikan temperature yang sesuai dengan kebutuhan yaitu temperatur dari lembar plastik agar dapat dibentuk.

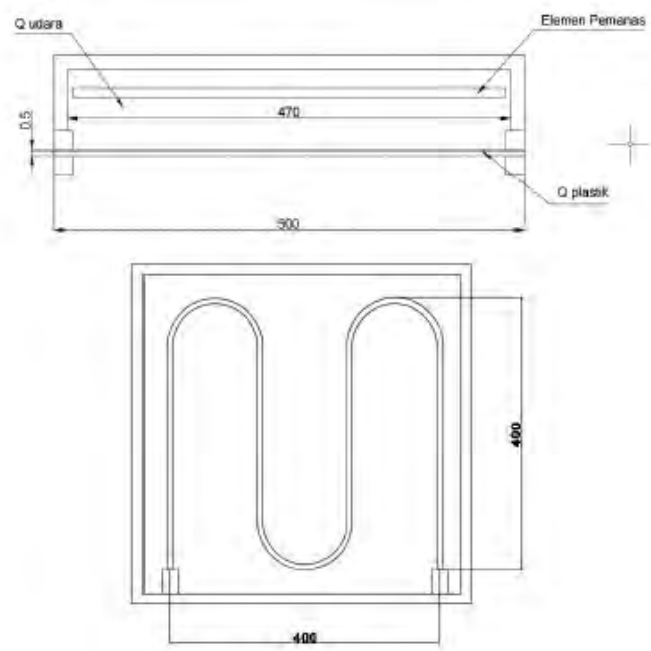

Gambar 7. Desain bentuk pemanas. 
Pemanas / Heater berada di bagian atas mesin vacuum forming. Elemen pemanas pada Heater mesin vacuum forming ini menggunakan jenis tubular heater yang dibentuk dengan profil seperti huruf $M$ seperti Gambar 7 agar penyebaran panas dapat meratadengan daya 800 Watt.

Mikrokontroler

Mikrokontroller adalah komputer berukuran mikro dalam satu chip IC yang terdiri dari prosesor, memori dan interface yang berupa input dan output yang dapat diprogram sesuai dengan kebutuhan[11]. Mikrokontroller yang digunakan pada rancang bangun ini adalah tipe Arduino Uno (Gambar 8) atas dasar pertimbangan biaya.

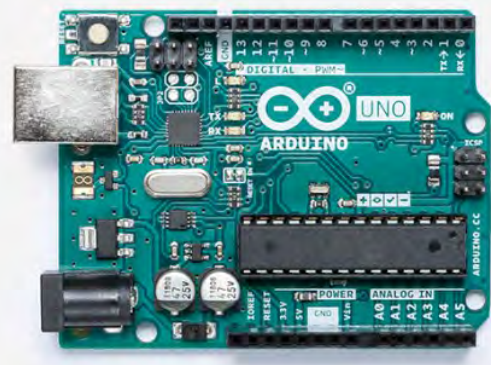

Gambar 8. Arduino Board[11].

Mikrokontroler ini hanya akan difungsikan sebagai alat untuk membaca sensor dan memberikan perintah pada actuator yang dikendalikan oleh perangkat lunak dari laptop via komunikasi serial.

Motor Vacuum

Motor ini digunakan untuk melakukan proses penyerapan udara yang terperangkap didalam bagian bawah plastik sehingga plastik akan mengikuti bentuk cetakan yang diletakkan pada meja (vacuum plate).

Human Machine Interface

Sebagai media penghubung antara operator dengan mesin (melalui antarmuka mikrokontroler), maka dibuat sebuah aplikasi dengan perangkat lunak menggunakan LabView[12]. Perangkat ini selain melakukan komunikasi baik membaca, menampilkan dan mengirimkan data juga melakukan pengambilan keputusan saat mesin beroperasi.

\section{HASIL DAN PEMBAHASAN}

Untuk mendapatkan hasil dari uji sistem, maka dilakukan terlebih dahulu langkah-langkah sebagai berikut.

Setup eksperimen memiliki desain seperti Gambar 9. Di mana Mesin terhubung dengan sensor dan actuator akan diproses oleh mikrokontroler. Data dari mikrokontroler akan dikirimkan menggunakan protokol komunikasi serial ke Laptop.

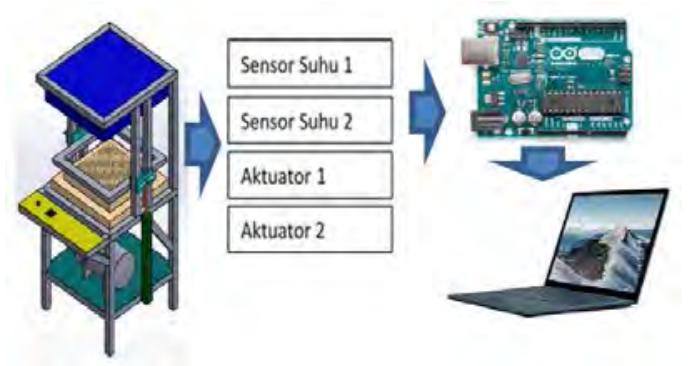

Gambar 9. Desain eksperimen

Setelah semua terhubung seperti pada Gambar 10, sistem siap dilakukan pengujian.

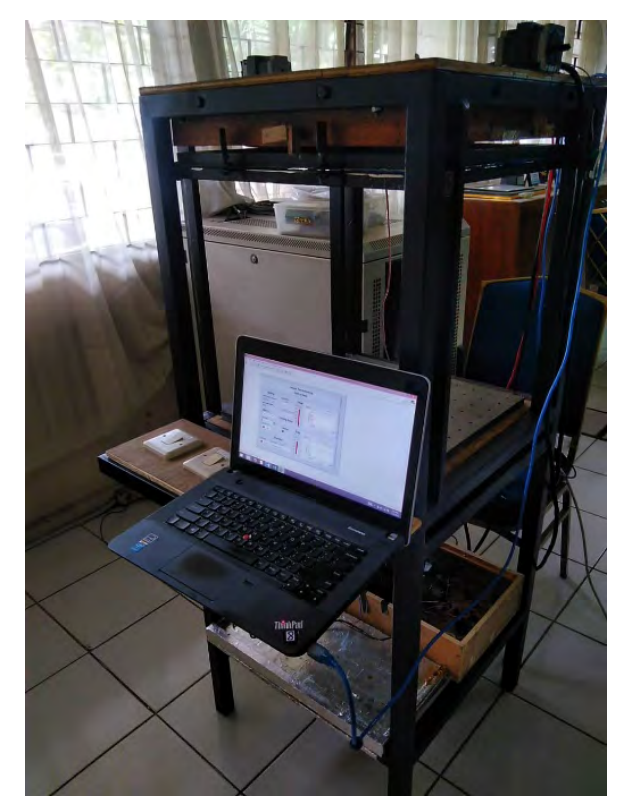

Gambar 10. Eksperimen pengendalian suhu dari mesin Vacuum Forming.

\section{Pengendalian}

Sistem Kontrol Pemanas 
Pemanas yang digunakan mampu menghasilkan suhu hingga lebih dari $300^{\circ} \mathrm{C}$. Sistem kontrol digunakan agar suhu yang dihasilkan oleh heater tidak melebihi suhu yang diizinkan oleh material plastik dimana masing-masing plastik memiliki karakter pemanasan seperti Tabel 1 di bawah ini.

Tabel 1. Tabel Transisi Plastik [13] .

\begin{tabular}{lcc}
\hline Material & $\begin{array}{c}\text { Glass Transition } \\
\text { Temperuture } \\
{\left[{ }^{\circ} \mathrm{C}\left({ }^{\circ} \mathrm{F}\right)\right]}\end{array}$ & $\begin{array}{c}\text { Melting } \\
\text { Temperuture } \\
{\left[{ }^{\circ} \mathrm{C}\left({ }^{\circ} \mathrm{F}\right)\right]}\end{array}$ \\
\hline Polyethylene (low density) & $-110(-165)$ & $115(240)$ \\
Polytetrafluoroethylene & $-97(-140)$ & $327(620)$ \\
Polyethylene (high density) & $-90(-130)$ & $137(279)$ \\
Polypropyleue & $-18(0)$ & $175(347)$ \\
Nylon 6.6 & $57(135)$ & $265(510)$ \\
Poly(ethylene terephthalate) (PET) & $69(155)$ & $265(510)$ \\
Poly(vinyl chloride) & $87(190)$ & $212(415)$ \\
\hline Polystyrenc & $100(212)$ & $240(465)$ \\
Polycarbonate & $150(300)$ & $265(510)$ \\
\hline
\end{tabular}

Jenis plastik yang digunakan adalah PVC rigid sheet dengan suhu pembentukan plastik berkisar antara $87^{\circ} \mathrm{C}$ s/d $212^{\circ} \mathrm{C}$. Set-point diatur pada suhu $300{ }^{\circ} \mathrm{C}$ agar plastik tidak meleleh karena panas yang terlalu tinggi. Cara kerja sistem ini yaitu ketika heater mencapai suhu $300{ }^{\circ} \mathrm{C}$ maka relayakan memutus aliran listrik sehingga heater tidak mengkonsumsi listrik, maka suhu akan turun, ketika suhu sudah turun melewati suhu $300{ }^{\circ} \mathrm{C}$ maka heater akan kembali mengkonsumsi listrik sehingga suhu heater naik kembali. Berdasarkan hasil pengujian yang dilakukan sistem ini mampu mengontrol suhu tetap di antara suhu pembentukan plastik.

\section{Pengujian Sistem Pemanas}

Pengujian kendali dari system pemanas diperlukan untuk mendapatkan karakter dari pemanas.

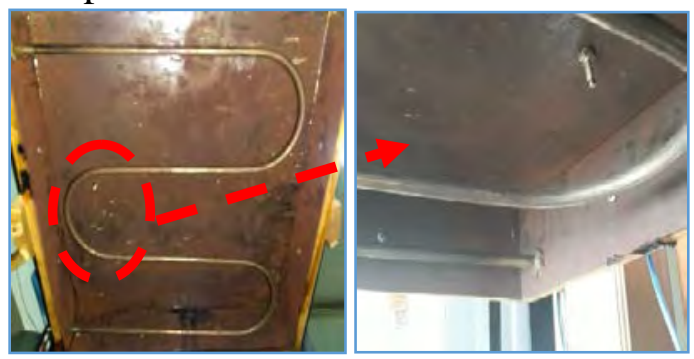

Gambar 11. Posisi sensor pemanas yang digunakan.
Suhu pada pemanas diukur oleh sensor panas (thermocouple) yang dipasang melekat pada pemanas. Selanjutnya dari uji kerja pemanas terhadap nilai temperatur yang diinginkan dapat dilihat pada Gambar 12.

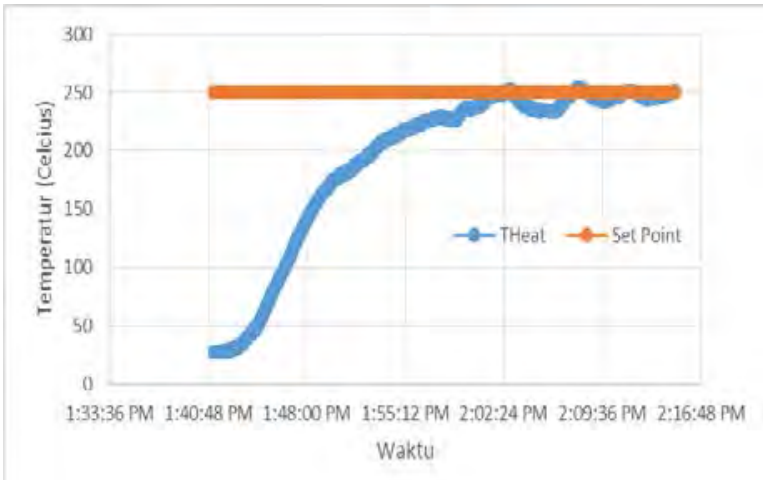

Gambar 12. Temperatur pemanas saat diaktifkan

Dari grafik tersebut terlihat bahwa untuk mencapai suhu yang diinginkan dari temperature ambien memerlukan waktu sekitar 20 menit. Bentuk dari kurva yang tidak rata dikibatkan factor angin disertai efek pendingin ruangan yang masih dapat melewati mesin karena bentuk yang terbuka.

Bentuk tampilan pada layar komputer (laptop) dengansistem Human Machine Interface menggunakan perangkat lunak LabView dapat dilihat pada Gambar 13.

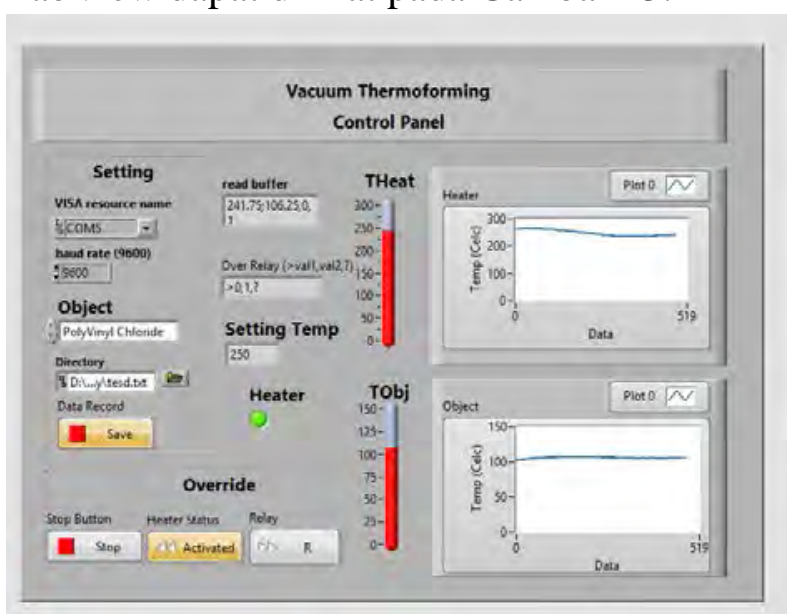

Gambar 13. Tampilan HMI pada layar monitor 
Pada tampilan tersebut terdapat beberapa buah setting yaitu port komunikasi, kecepatan transfer data, jenis obyek (plastik), dan lokasi penyimpanan data. Selanjutnya indikator yang dimunculkan adalah temperatur dari heater dan obyek dalam bentuk angka maupun grafik.

Untuk merealisasi HMI tersebut maka pemrograman berbasis grafis digunakan.Dengan editor perangkat lunak LabView versi 15, hasil pemrograman seperti Gambar 14.Program tersebut bertujuan untukmemfasilitasi proses pembacaan data dari mikrokontroler menggunakan protocol serial untuk selanjutnya digunakan untuk mengendalikan pemanas/heater. Selain itu pada program memungkinkan untuk dilakukan penyimpanan data jika diperlukan.

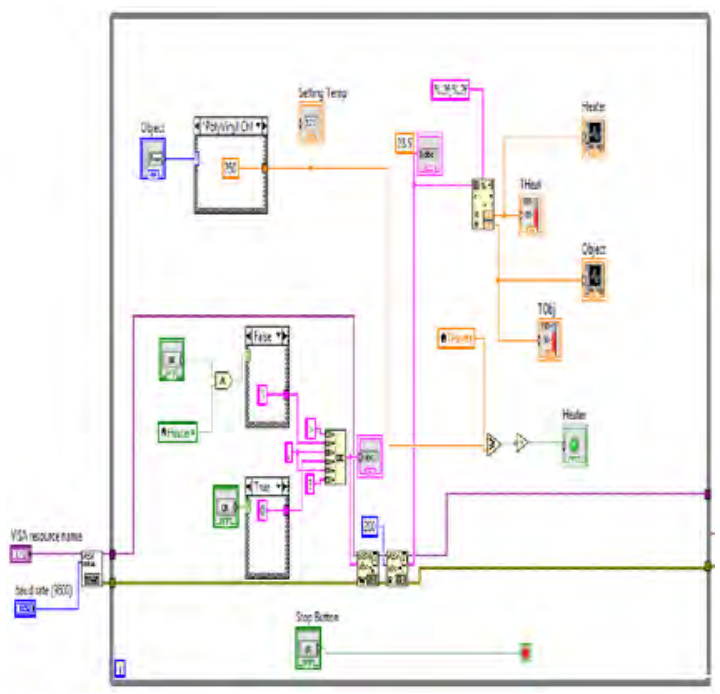

Gambar 14. Program HMI dengan

\section{LabView}

Pada saat uji melalui salah satu jenis plastik (PVC) didapatkan bahwa temperature heater dijaga agar konstan pada $250^{\circ} \mathrm{C}$. Dengan temperature tersebut suhu pada obyek (PVC) dapat dijaga sebesar $110^{\circ} \mathrm{C}$ (yaitu suhu untuk pembentukan plastik tipe tersebut). Ini menunjukan bahwa desain mekanik dari system terdapat panas yang hilang.
Hasil pengendalian suhu dari mesin yang dibuat dengan obyek plastik PVC dapat dilihat pada Gambar 15. Bahwa pengendali dapat menjaga suhu yang cenderung konstan pada $110^{\circ} \mathrm{C}$ dengan mengendalikan temperatur heater pada $250^{\circ} \mathrm{C}$. Terlihat bahwa terdapat fluktuasi suhu yang lebih besar dibandingkan dengan suhu obyek yang dikendalikan.

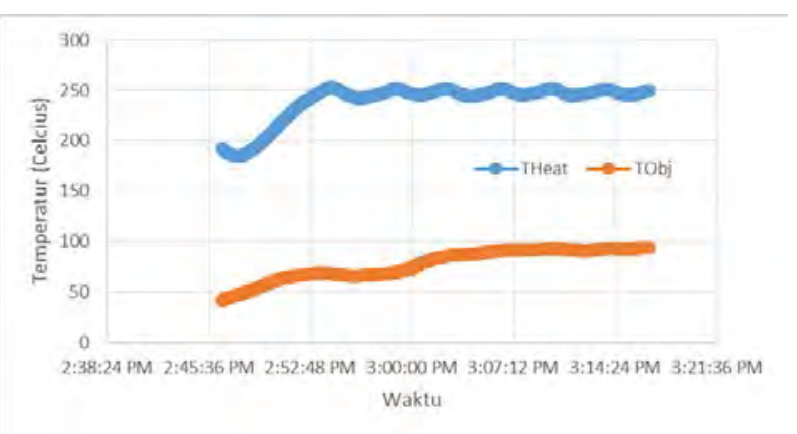

Gambar 15. Perbandingan suhu pemanas dan obyek lembar plastik.

Memerlukan waktu sekitar 15 menit untuk memanaskan lembar plastik agar dapat dibentuk sesuai dengan cetakan.

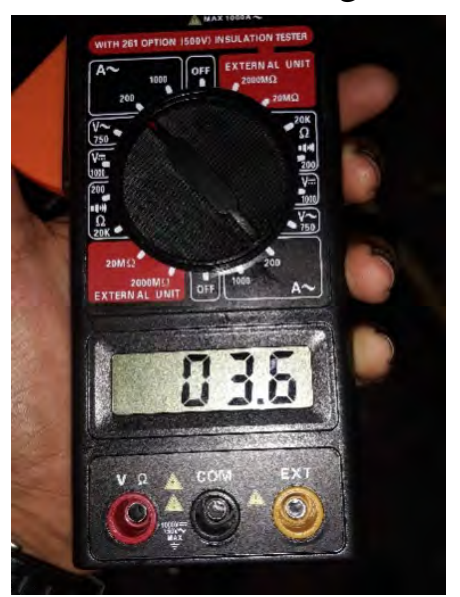

Gambar 16. Pengukuran arus pada pemanas

Konsumsi arus pada mesin dibutuhkan agar dapat diketahui berapa konsumsi daya listrik yang dibutuhkan. Dengan Amperemeter seperti Gambar 16, arus rata-rata didapatkan untuk dicari besaran dayanya melalui formula berikut. 
$P=V . I$

Dimana $P, V$, dan $I$ secara berturutan adalah Daya (W), Tegangan (V) dan Arus (A).

$P=220 \mathrm{~V} \cdot 3.6 \mathrm{~A}$

$P=792 W$

Sementara Energi yang dikonsumsi adalah Daya selama kurun waktu tertentu.

$W=P . t$

$W=792 \cdot 0.5$ hours

$W=396$ Whours

Dari konsumsi energy tersebut dapat diketahui perkiraan biaya listrik yang dikeluarkan oleh pengguna. Pada saat pengoperasian pertama maka memerlukan waktu 30 menit. Sehingga biaya kurang lebih adalah.

Biaya $=W x R p .1 .500,00 / k W h$ (4)

Biaya $=0.4 J \times R p .1 .500,00 / k W h$

Biaya $=R p .375,00$

\section{KESIMPULAN}

Dari penelitian ini didapatkan kesimpulan bahwa Mesin thermo forming untuk skala usaha kecil menengah memiliki karakter pemanas yang stabil dengan waktu 20 menit. Sementara transfer panas pada bahan plastik tipe PVCmemerlukan waktu 15 menit. Pengendalian dengan sistem HMI mempermudah pengguna untuk mengoperasikan sekaligus melakukan monitoring mesin. Sementara untuk biaya operasional dari proses pemanasan dari plastik yang akan dicetak biayanya tidak mahal sesuai dengan kemampuan pengguna. Sebagai tambahan, bahwa dengan perangkat lunak sebagai antarmuka (interface) mesin, dapat dilakukan pemutakhiran sistem untuk dikembangkan. Dari hasil yang diperoleh maka didapatkan rekomendasi, perubahan system mekanik dan penambahan elemen control seperti aliran udara agar dapat mengurangi panasyang terbuang dan memberikan respon yang cepat.

\section{UCAPAN TERIMA KASIH}

Terima kasih kepada Politeknik Negeri Jakarta atas dukungan terhadap Penelitian ini melalui skema Penelitian Unggulan Perguruan Tinggi 2018.

Selanjutnya terimakasih kepada saudara Heneng Sukmo Manembah, Daffa Adli Munandar dan Fahmi Haidi yang telah membantu dalam pembuatan system mekanik dari mesin Vacuum Thermoforming.

\section{DAFTAR PUSTAKA}

[1] Alam O., et al., "Characteristics of plastic bags and their potential environmental hazards," Resources, Conservation \& Recycling, 2017.

[2] Arduino. Available: www.arduino.cc. 03 Maret 2018

[3] F. I. Ltd. Formech 2240 Large Format Vacuum Forming Machine. Available: http://formech.com/product/2440/

[4] Gosta D. R.. Konsumsi Plastik Naik $5 \%$. Available: http://www.kemenperin.go.id/artike 1/16799/Konsumsi-Plastik-Naik-5. 28 Desember 2016

[5] Greenfeet, 2004. Paper Vs. Plastic - The Shopping Bag Debate Available:

http://www.greenfeet.net/newsletter /debate.html. 11 September 2015

[6] Luijsterburg B., Goossens, H, "Assessment of plastic packaging waste: material origin methods, properties. ," Resource. Conservation. Recycling, 2014.

[7] I. Elektronik, "Manual MAX 6675 K-Type Thermocouple Temperature Sensor," Indowarehouse, Ed., ed. Semarang, 2014.

[8] N. Instrument. LabView. Available: http://www.ni.com/enid/shop/labview/labviewdetails.html. 5 Agustus 2018

[9] Omron. Proximity Switch [Online]. 
[10] Scheider.

Available:

https://motion.schneiderelectric.com/downloads/quickrefere nce/NEMA23.pdf

[11]S. P. M. Inc., "Thermoforming Equipment," S. P. M. Inc., Ed., ed. Quebec: Starview Packaging Machinery Inc, 2012.

[12]T. Soft. Vacuum Forming Thermoforming Equipment. Available:

https://www.techsoft.co.uk/Worksh opEquipment/ThermoformingEqui pment/VacuumFormers

[13] W. D. C. Jr., Materials Science and Engineering. Iowa, 2007. 
Sonki Prasetya dkk, Kontrol Vacuum Forming HMI..... 